\title{
Study on Wind Vibration Coefficient Chang Rule of Cup Type Transmis- sion tower Considered Abrupt Change in Stiffness
}

\author{
Xiufeng $\mathrm{Wu}^{*}$ and Hongfang $\mathrm{Li}$
}

Institute of Architecture and Civil Engineering, Liaoning Technical University, China

\begin{abstract}
Wind load is the key and sensitive for tower structure but national standards tend to think that level stiffness change of cup type transmission tower is uniform along the height. The structure stiffness change of cup type transmission tower was simulated innovatively and found its nonuniformity. The result shows that the structural stiffness uniformly changes along the height when the flow direction parallel to the cross arm while the stiffness of crank arm and cross arm has mutations when the flow direction is vertical to the cross arm. Horizontal stiffness change causes a significant change of wind vibration coefficient. A simulation analysis was performed about wind-induced response of cup-tower to obtain the change rule of wind vibration coefficient. Furthermore, proposed the approximate calculation formula of wind vibration coefficient at crank arm and cross arm.
\end{abstract}

Keywords: Cup type transmission tower, wind-induced response, wind vibration coefficient, change rule.

\section{INTRODUCTION}

The power transmission project plays an important role in changing the uneven distribution of our country's energy resources. Transmission projects extend thousands of kilometers and cost billions of dollars to construct and maintain. The structure of cup-tower is one kind of high supple structure, when affecting by wind, its dynamic response will be affected. The wind force is one of the important loadings for the design of high supple structure. So it is an important aspect in the field of research and design on wind-induced response of cup-tower under the action of random wind load.

Some scholars have done related research on wind vibration response of transmission towers. Since the early 1960s, some scholars in Japan and Europe took the lead to research the wind vibration coefficient of transmission line tower [1-3]. Armitt et al. [2] summaried and gived the research results of European scholars on the aspects of equivalent wind load of transmission line and the summary report submitted by Manuzio and Pairs [3] was one of the most important. In 1979, the gust response factor to calculate the static equivalent wind load of power transmission line tower system given out by Davenport $[4,5]$ which adopted by international power and Canada overhead transmission line design guidelines but expression is different. Holmes established the analytical expression of lattice tower wind vibration response factor and studied the influence of aerodynamic damping on wind vibration responses [6]. In China, li et al. [7-10] studied the dynamic response of transmission tower in the time domain and the frequency domain, respectively. Liang et al. [11-13] developed the time marching generating method of fluctuating wind and found the applicability of simulated wind timemarching for wind-induced response analysis. Deng et al. $[14,15]$ conducted the wind tunnel test on an aeroelastic model and analyzed the wind-induced response of model.

Although a lot of scholars do research on wind vibration responses of transmission tower, there is no such document for reference about the variation of equivalent stiffness and wind vibration coefficient along the height. To solve this problem, we study the change rule of stiffness and wind vibration coefficient of cup-tower for different flow direction.

\section{STIFFNESS MUTATION EFFECT}

5 cup-towers of different height have been chosen as the research object and the related parameters were list in Table 1. A finite-element computer program ansys 12.0 is selected to establish the models. As shown in Fig. (1), the cup type transmission tower includes five towers modeled by beam element and link element. And parallel to the direction of cross arm is $\mathrm{x}$ axis while vertical cross arm is $\mathrm{y}$ axis direction.

The model is reasonable by analyzing the vibration mode and frequency. Then analyzed the equivalent stiffness of cup-towers, Fig. (2) shows the change of equivalent stiffness. For the cross section of tower body is a square, so the equivalent stiffness of Longitudinal (parallel to the cross arm) is equal to the equivalent stiffness of $y$ direction (vertical to the cross arm). Meanwhile, the quality and related parameters are the same of crank arm and cross arm of the 5 cup-towers, so the value of equivalent 
Table 1. Model parameters of cup-towers.

\begin{tabular}{|c|c|c|c|c|c|}
\hline Model & $\begin{array}{c}\text { Total Height } \\
(\mathbf{m})\end{array}$ & Nominal Height (m) & Bottom Width (m) & Crank Arm Height (m) & Cross Arm Height (m) \\
\hline \hline T39 & 42.5 & 39 & 7.480 & 8.5 & 3.5 \\
\hline T42 & 45.5 & 42 & 7.991 & 8.5 & 3.5 \\
\hline T45 & 48.5 & 45 & 8.502 & 8.5 & 3.5 \\
\hline T48 & 51.5 & 48 & 9.014 & 8.5 & 3.5 \\
\hline T51 & 54.5 & 51 & 9.525 & 3.5 \\
\hline
\end{tabular}

stiffness is equal. Fig. (2) shows that the equivalent stiffness varies linearly with any height in $\mathrm{x}$-direction. The equivalent stiffness of tower body varies linearly while in the crank arm are altered obviously. The abrupt change in stiffness of crank arm is more obvious with higher tower then smaller numerical in cross arm.

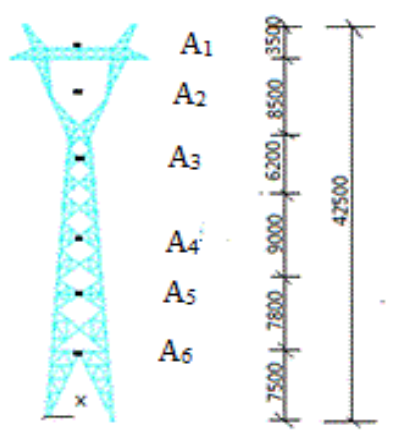

a.T39

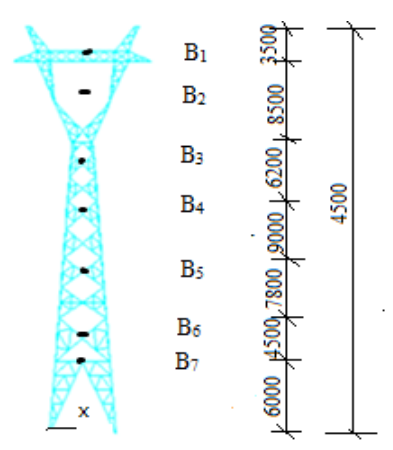

b.T42

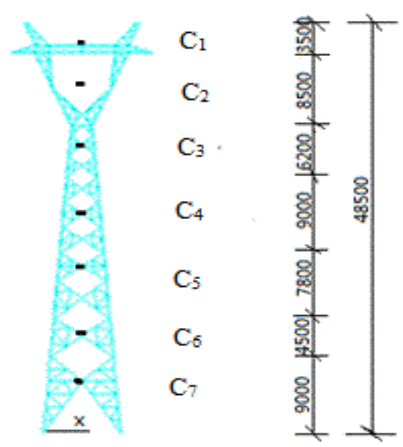

c.T45

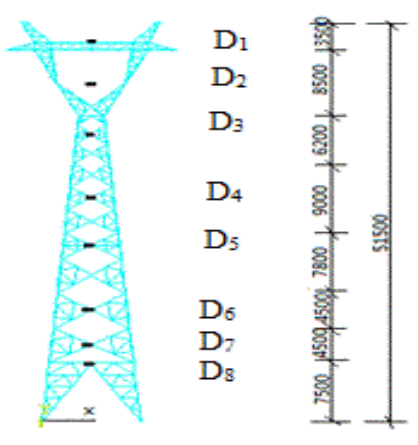

d.T48

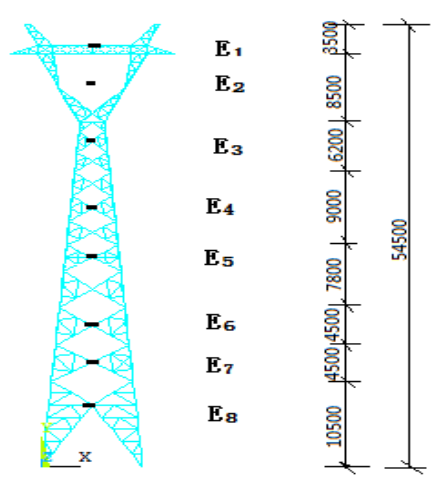

e.T51

Fig. (1). Finite element models and equivalent point.

\section{RANDOM VIBRATION THEORY AND SIMULA- TION OF WIND}

\subsection{Random Vibration Theory}

Wind load is composed of mean wind and fluctuating wind. The magnitude and direction of mean wind also known as static wind load is constant at a certain time period. The mathematical expression used to define the mean wind is given in the following form:

$p_{c}(z)=\mu_{s}(z) \mu_{z} A_{f} \omega_{0}$

in which $\mu_{s}(z)$ represents the shape factor of structure, $\mu_{z}$ is the wind pressure height coefficient, $A_{f}$ is the projected 


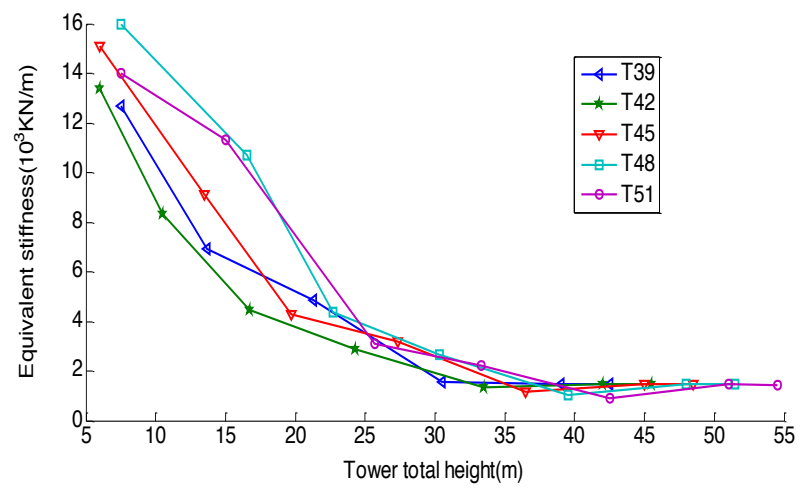

a. Equivalent stiffness in $\mathrm{x}$ direction

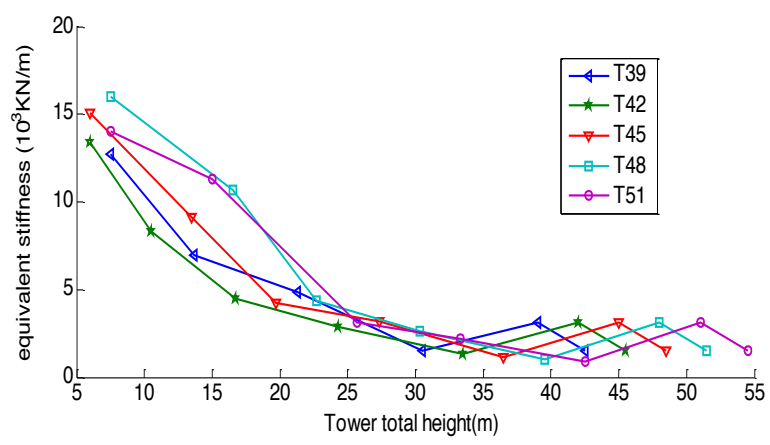

b. Equivalent stiffness in y direction

Fig. (2). The change curve of equivalent stiffness.

area under wind pressure of component, $\omega_{0}$ is the value of standard wind pressure.

The magnitude and direction of fluctuating wind change with the time and the period is shorter. Considering its randomness, it should be calculated based on random vibration theory. The calculation of fluctuating wind load is more complex, so it is transformed into equivalent static wind load to calculate.

The vibration differential equation for multi-degree of freedom structure system is shown as follow [16]:

$M \ddot{X}(t)+C \dot{X}(t)+K X(t)=F(t)$

Where $X=\phi q$ and by mode-superposition method equation (2.2) can be extended to

$\ddot{q}_{i}(t)+2 \xi_{i} \omega_{i} \dot{q}_{i}(t)+\omega_{i}^{2} q_{i}(t)=F_{i}(t)$

in which, $\mathrm{q}_{\mathrm{i}}(\mathrm{t})$ is the generalized coordinates of $\mathrm{i}$ model shape, $\xi_{i}$ and $\omega_{i}$ are the damping ratio and circular frequency of point $\mathrm{i}, F_{i}(t)$ is the generalized fluctuating wind load of point $\mathrm{i}$.

Based on random vibration theory, the displacement power spectral density function is

$$
S_{z}(z, \omega)=\sum_{i=1}^{\infty} \sum_{j=1}^{\infty} \phi_{i}(z) \phi_{j}(z) \bullet H_{i}(\omega) H_{j}(\omega) S_{F_{i} F_{j}}(\omega)
$$

where $H_{i}(\omega)$ and $H_{j}(\omega)$ solved depending on (2.3)are the frequency response function of points $\mathrm{i}$ and $\mathrm{j}, S_{F_{i} F_{j}}(\omega)$ is the the cross-spectral density function of generalized force.

For stimulus-response of natural frequency is small, the constructional damping is less, so the influent of cross-term can be neglected. Equation (2.4) can be written as

$$
S_{z}(z, \omega)=\sum_{i=1}^{\infty} \phi_{i}^{2}(z) H_{i}^{2}(\omega) S_{F_{i}}(\omega)
$$

The mean square deviation of displacement response at point $i$ can be obtained by integral and extraction of root of (2.5). The displacement response is

$$
y_{i}=g \sigma_{y_{i}}
$$

where $\sigma_{r i}$ is the mean square deviation of displacement response, $\mathrm{g}$ is the peak factor. The equivalent inertia force of node is

$$
P_{d}(z)=\sqrt{\sum_{i=1}^{n}\left(M_{i} \omega_{i}^{2} g \sigma_{y_{i}}\right)^{2}}
$$




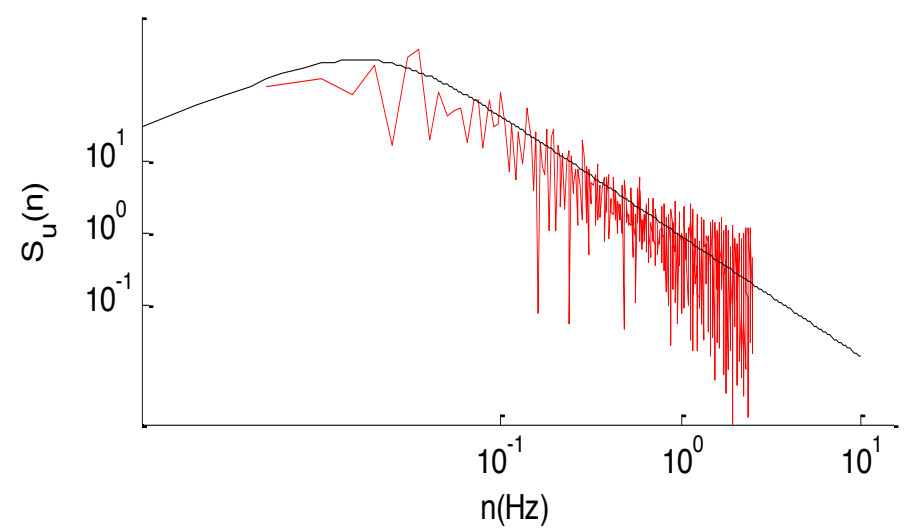

Fig. (3). Power spectral density function.

Equation (2.7) can be reduced to

$P_{d}(z)=g m(z) \sigma_{x}(z)$

in which $\mathrm{m}(\mathrm{z})$ is the lumped mass of a certain height, $\sigma_{x}(z)$ is the mean square root acceleration, $\mathrm{g}=2.5$.

\subsection{Simulation of Wind Load}

Assumed that the basic wind velocity is $\mathrm{V}_{10}=25 \mathrm{~m} / \mathrm{s}$ and simulated the fluctuating wind based on Davenport spectrum to obtain the fluctuating wind velocities at any height of five models. The power spectral density function simulated is shown as Fig. (3).

Fig. (3) shows that the power spectral density function simulated is closed to the Davenport spectrum. It is seen from the figure that the simulated result is well.

\section{WIND-INDUCED RESPONSE ANALYSIS OF CUP TYPE TOWERS}

\subsection{Wind-induced Response Contrastive Analysis of Tower Body and Crank Arm}

Study on the wind-induced response of five tower models in $\mathrm{x}$-direction and $\mathrm{y}$-direction and obtain the acceleration response of each equivalent point. In this study, the acceleration response of crank arm and the top node of tower body have been listed.

Fig. (4) and Fig. (5) show that both the acceleration time histories curves of the top node of tower body and crank arm slightly increase with increasing of the tower height in $\mathrm{x}$ direction, and there are no significant difference between them, however, the acceleration time histories curves of the top node of tower body and crank arm change significantly in $y$-direction. The variation of the top node of tower body is more evident than the crank arm and the curves of the top node of tower body are close to the crank arm curves with increasing of the tower height.

\subsection{Wind-induced Response Contrastive Analysis of Cross Arm}

Meanwhile, the acceleration time histories curves of cross arm of towers are shown in Fig. (6). Fig. (6) show that the change of acceleration is not obvious with increasing of the tower height in $\mathrm{x}$-direction while it changes significantly in $\mathrm{y}$-direction.

\section{WIND VIBRATION COEFFCIENT SIMULATEDN AND CHANGE RULE OF CUP TOWER}

\subsection{Wind Vibration Coefficient Simulated}

Currently, the analysis of wind vibration coefficient focused on the load response, the expression form of wind vibration coefficient is [17]

$\beta_{z}=\frac{P_{d}(z)+P_{c}(z)}{P_{c}(z)}=1+\frac{g m(z) \sigma_{x}(z)}{\mu_{s}(z) \mu_{z} A_{f} \omega_{0}}$

The acceleration response obtained before was substituted in equation (5.1). The wind vibration coefficient as shown in Table $\mathbf{2}$ is analyzed in terms of $\mathrm{x}$-direction and $\mathrm{y}$ direction, respectively.

The results in Table 2 show that wind vibration coefficient uniformly changes in $\mathrm{x}$-direction with increasing of the tower height. The wind vibration coefficient uniformly changes along the height of tower body, however, its variation was very evident in crank arm and cross arm because of the abrupt change in stiffness.

\subsection{Change Rule of Wind Vibration Coefficient in Crank Arm}

The wind vibration coefficient of crank arm uniformly changes in $\mathrm{x}$-direction, so it can be calculated according to the general method. There is a close relationship between the wind vibration coefficient and stiffness in crank arm in ydirection. So assumption that the wind vibration coefficient 


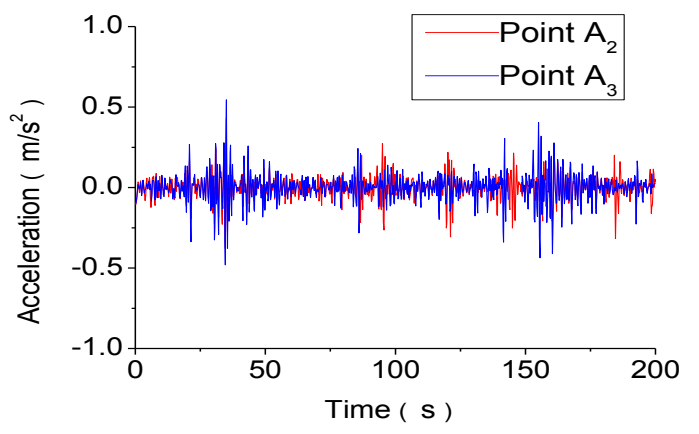

a. model of T39

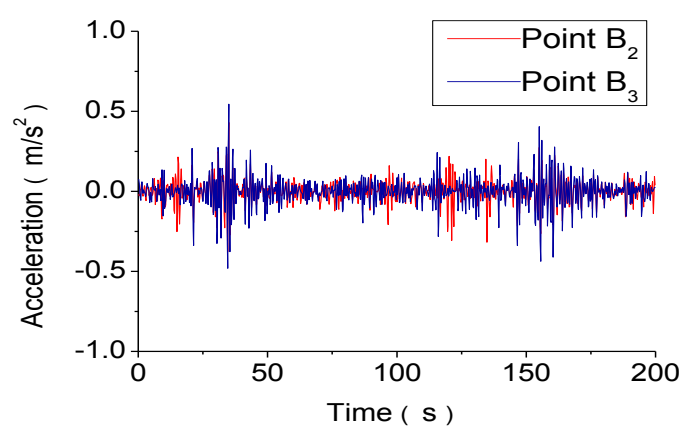

b. model of T42
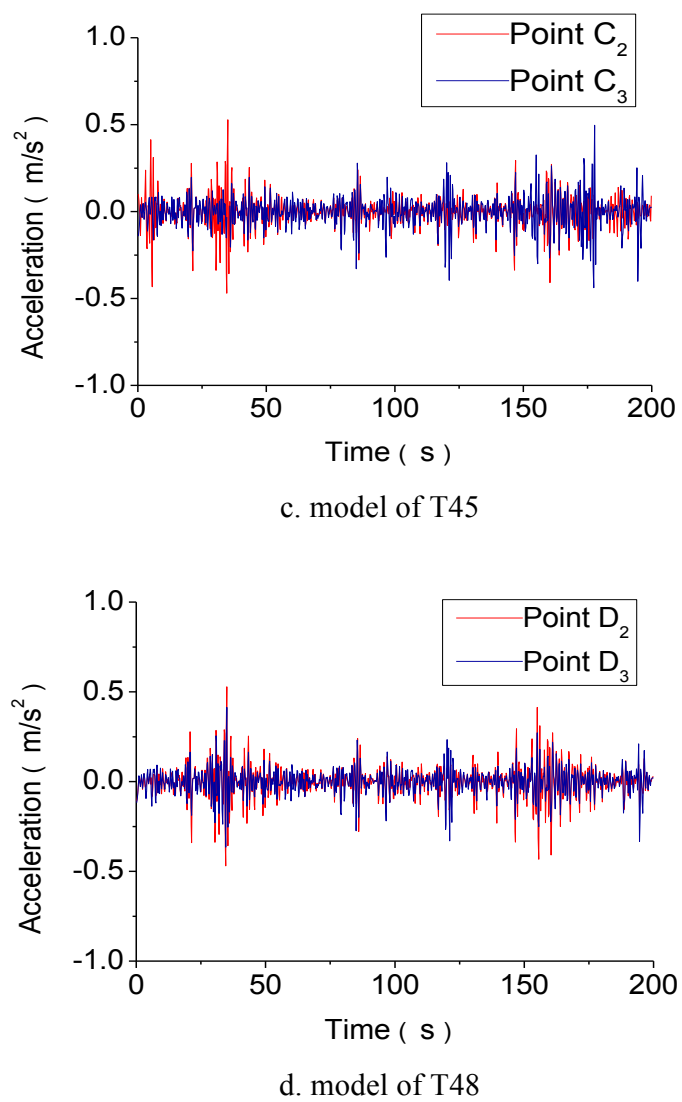

Fig. (4). Contd... 


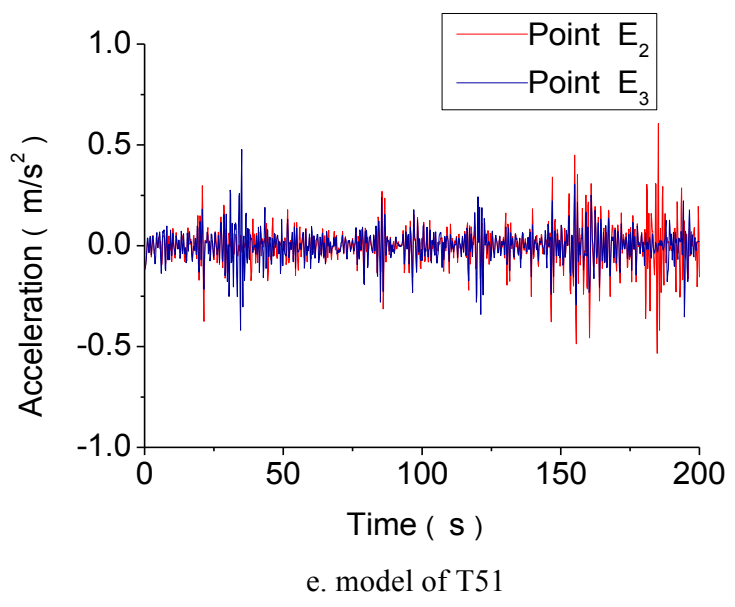

Fig. (4). Acceleration time history comparison of crank arm with the top node of tower body in x-direction.
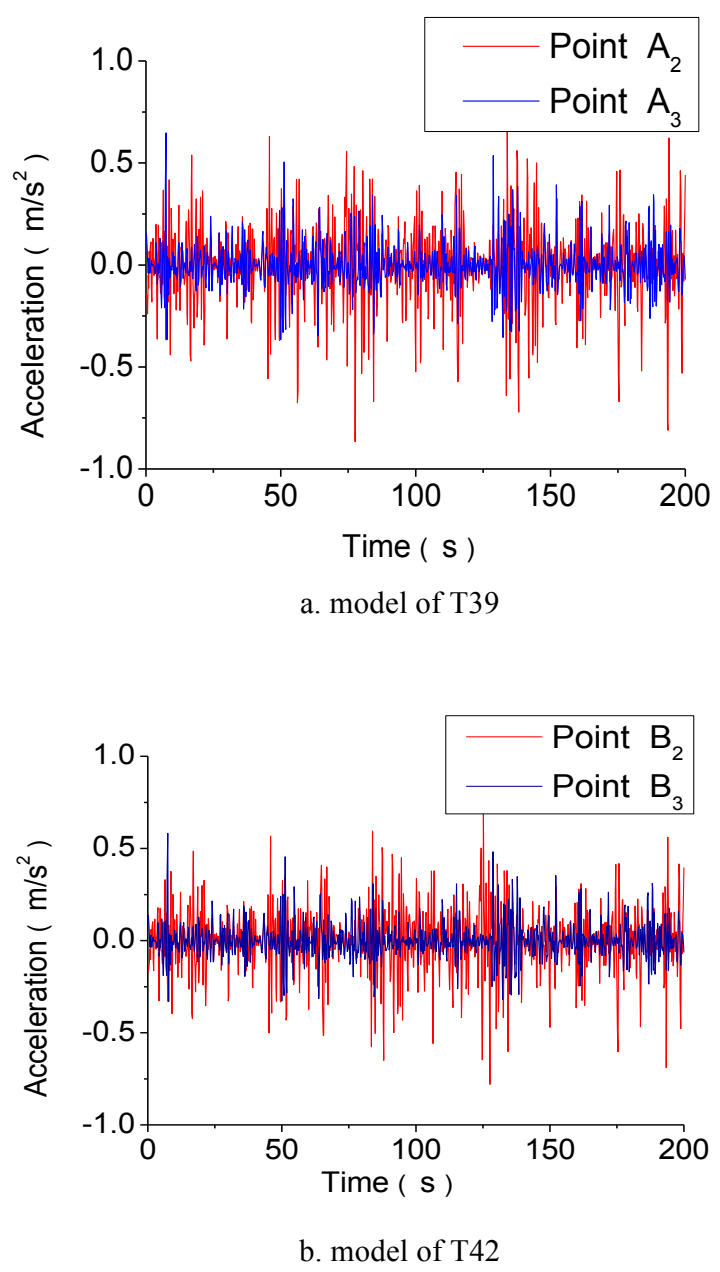

Fig. (5). Contd... 

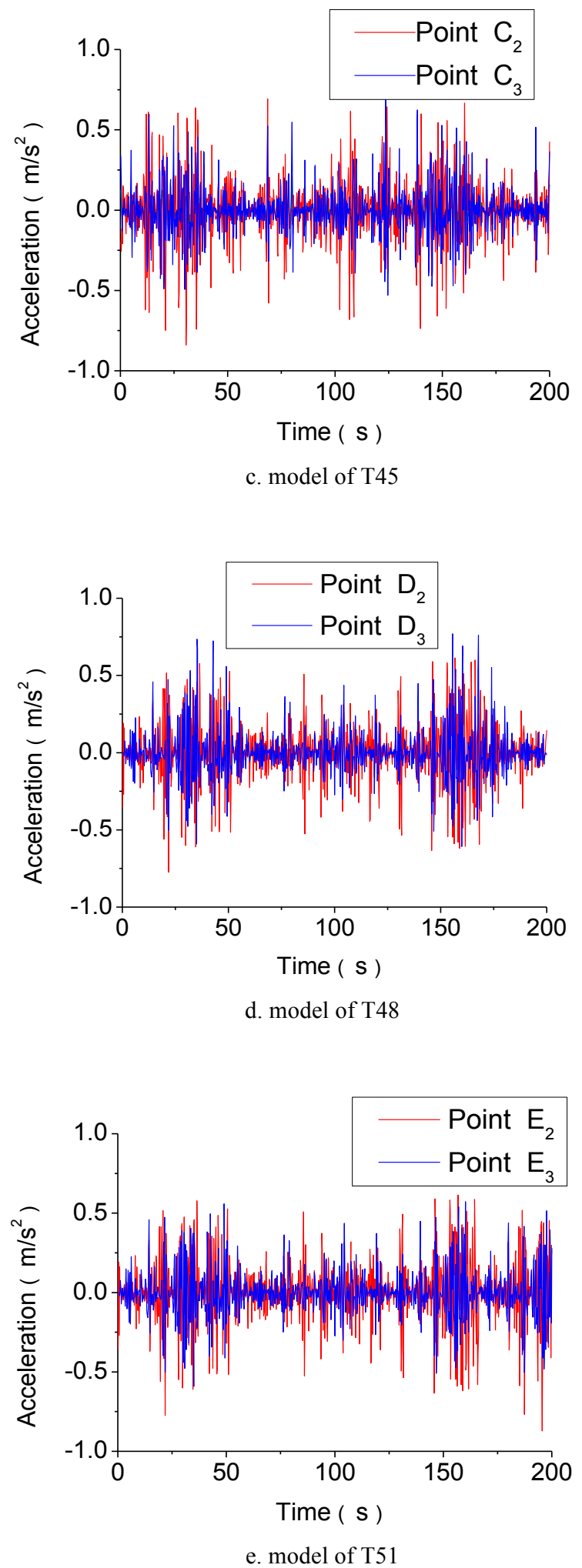

Fig. (5). The acceleration time history comparison of crank arm with the top node of tower body in y-direction. 

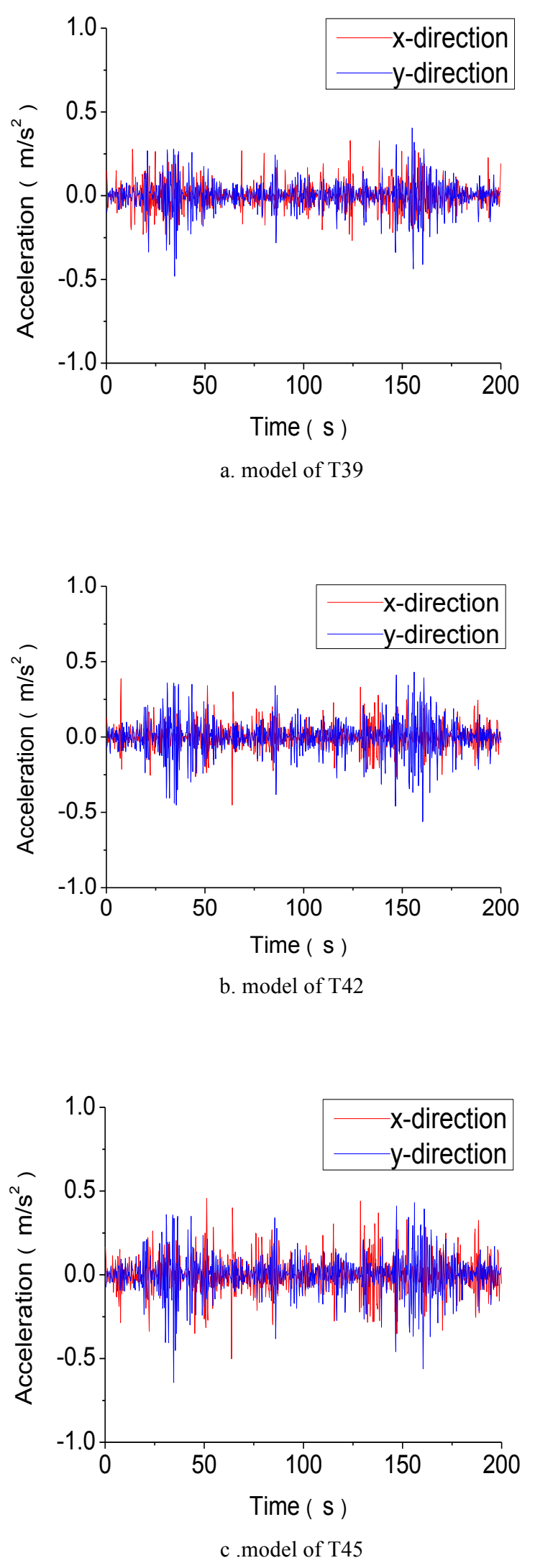

Fig. (6). Contd... 

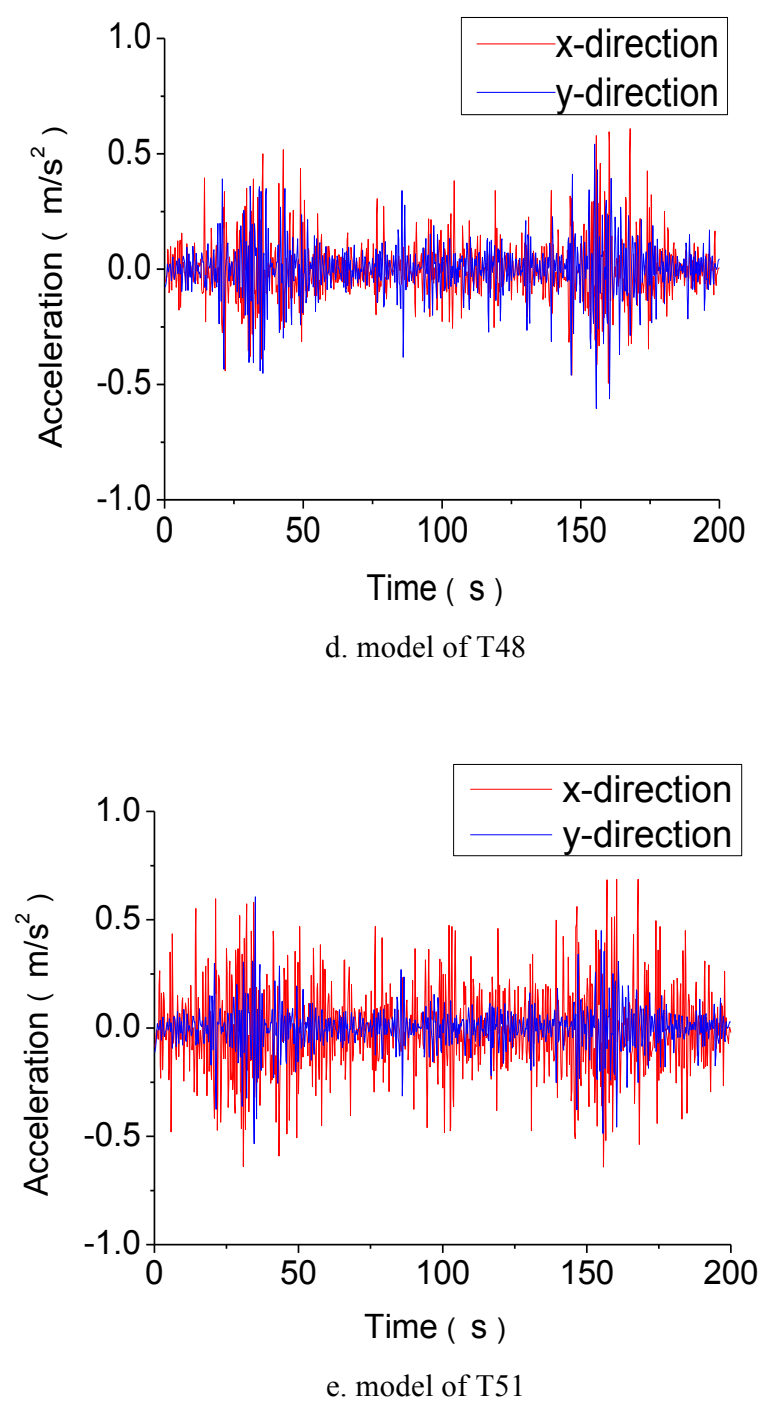

Fig. (6). The acceleration time history of cross arm in $\mathrm{x}$-direction and y-direction.

Table 2. Simulated result of wind vibration coefficient.

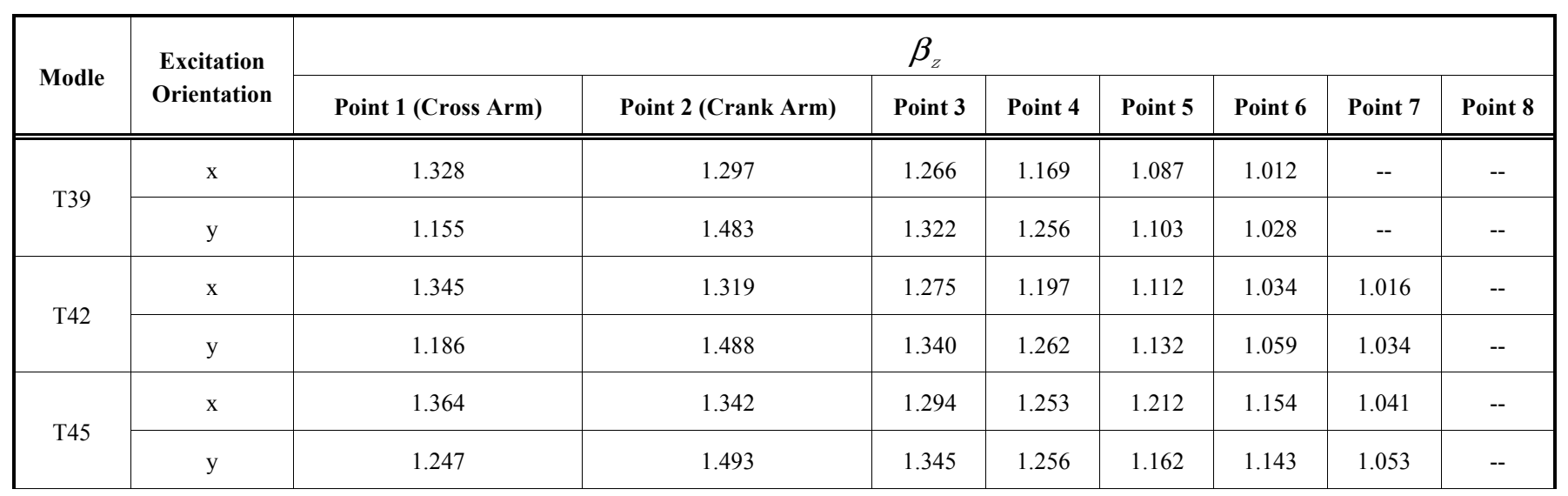


Table 2. contd...

\begin{tabular}{|c|c|c|c|c|c|c|c|c|c|}
\hline \multirow{2}{*}{ Modle } & \multirow{2}{*}{$\begin{array}{l}\text { Excitation } \\
\text { Orientation }\end{array}$} & \multicolumn{8}{|c|}{$\beta_{z}$} \\
\hline & & Point 1 (Cross Arm) & Point 2 (Crank Arm) & Point 3 & Point 4 & Point 5 & Point 6 & Point 7 & Point 8 \\
\hline \multirow{2}{*}{$\mathrm{T} 48$} & $\mathrm{x}$ & 1.375 & 1.351 & 1.313 & 1.261 & 1.204 & 1.108 & 1.054 & 1.031 \\
\hline & $\mathrm{y}$ & 1.278 & 1.507 & 1.359 & 1.250 & 1.170 & 1.075 & 1.036 & 1.026 \\
\hline \multirow{2}{*}{ T51 } & $\mathrm{x}$ & 1.391 & 1.376 & 1.335 & 1.254 & 1.211 & 1.198 & 1.176 & 1.074 \\
\hline & $\mathrm{y}$ & 1.293 & 1.510 & 1.367 & 1.245 & 1.200 & 1.163 & 1.125 & 1.039 \\
\hline
\end{tabular}

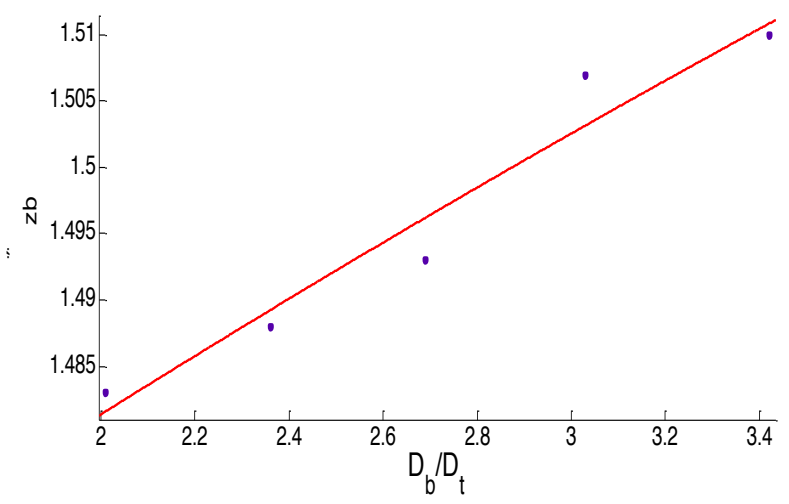

Fig. (7). The wind vibration coefficient of crank arm and Gaussian fitting.

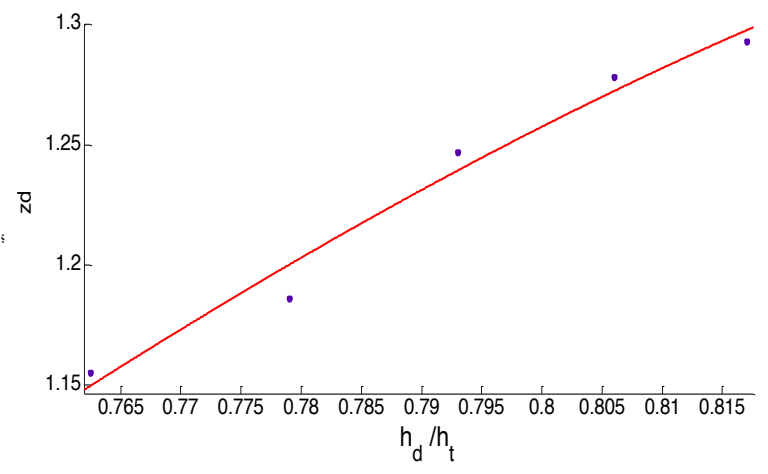

Fig. (8). The wind vibration coefficient of cross arm and Gaussian fitting.

in crank arm has something to do with the stiffness ratio between the crank arm and the top of tower body, meanwhile, it has relationship with the wind vibration coefficient at the top of tower body. The fitting curve obtained by Gaussian function is shown in Fig. (7) and the relations can be written as

$$
\beta_{z b}=1.591 * \exp \left\{-\left[\left(\mathrm{D}_{\mathrm{b}} / \mathrm{D}_{\mathrm{t}}-11.56\right) / 35.71\right]^{\wedge} 2\right\}
$$

where $D_{b}$ and $D_{t}$ are the equivalent stiffness of the top of tower body and crank arm.

Fig. (7) show that with the increasing of stiffness ratio between the crank arm and the top of tower body the wind vibration coefficient in crank arm increases.

\subsection{Change Rule of Wind Vibration Coefficient in Cross Arm}

The wind vibration coefficient of cross arm uniformly changes in $\mathrm{x}$-direction, so it also can be calculated according to the general method. It also has a close relationship between the wind vibration coefficient and stiffness in cross arm in y-direction while the stiffness ratio between crank arm and cross arm of five towers is the same because of the equal stiffness in them. So assumed that the wind vibration coefficient in cross arm is related to the equivalent point height ratio between the cross arm and the top of tower body and it has relationship with the wind vibration coefficient at the top of tower body. Also fitting curve obtained by Gaussian is shown in Fig. (8) and the relations is 


$$
\beta_{z d}=1.393 * \exp \left\{-\left[\left(\mathrm{h}_{\mathrm{t}} / \mathrm{h}_{\mathrm{d}}-0.9016\right) / 0.3174\right]^{\wedge} 2\right\}
$$

in which $h_{t}$ and $h_{d}$ are the equivalent point height of cross arm.

Fig. (8) shows that with the increasing of equivalent point height ratio between the cross arm and the top of tower body the wind vibration coefficient in cross arm increases.

\section{CONCLUSION}

The cup type transimission tower is one of the most complicated structures. The effect of wind-induced response and wind vibration coefficient of cup type transmission tower has been investigated in this paper. And the equivalent stiffness are also developed and taken into account in the analysis. Following conclusions can be obtained based on the above studies.

(1) The case of flow direction in $x$-direction does not produce the significant response in the stiffness and wind vibration coefficient.

(2) The stiffness and wind vibration coefficient has mutations when the flow direction is vertical to the cross arm.

(3) The flow direction has an obvious effect on the response of transimission tower. In order to obtain the variation of wind vibration coefficient, more flow direction should be considered to analyze it.

(4) In order to obtain a representative analysis of the system, an accurate estimation of the wind velocity is required.

This study demonstrates that the flow direction is very important to tower. Based on the obtained results, it should be noted that many studies of wind-induced response have been reported on transimission tower, very limited study on stiffness of cup type tower can be found in the literature. More studies are deemed necessary to further investigate on the stiffness and wind-induced response of this kind of highrise structure.

\section{CONFLICT OF INTEREST}

The authors confirm that this article content has no conflict of interest.

\section{REFERENCES}

[1] Catanheta M. Dynamic behaviour of overhead power lines subjected to the action of wind. GIGRE Report 22-08, Paris, 1970.

[2] Armitt J, Cojan M, Mazunio C, et al. Calculation of wind loadings on components of overhead lines. Proceedings of IEE, 1975, 22(11): 1242-1252.

[3] Mazunio C, Paris L.Statistical determination of wind loadings effects on overhead lines conductors. GIGRE Report, 231, 1964.

[4] Davenport A G.Gust response factors for transmission line loading//Cermark J E.Porceeding of the fifth international conference on wind engineering. New York; Pergamon Press, 1979: 899909.

[5] Loredo-Souza A M, Davenport A G.A novel approach for wind tunnel modeling of transmission lines. Journal of Wind Engineering and Industrial Aerodynamic, 2001, 89: 1017-1029.

[6] Holmes J D. Along-wind response of lattice towers. Part I: derivation of expression for gust response factors. Engineering Structures, 1994, 16(4):287-292.

[7] H.-N. Li,H.-F. Bai, "Dynamic behavior and stability of transmission tower-line system under wind (rain) forces," China Civil Engineering Journal, vol. 41, no.11, pp. 31-38, 2008 (Chinese).

[8] G.-H. Liu, H.-N. Li, "Analysis and optimization control of windinduced dynamic response for high-voltage transmission towerline system," Proceedings of the Chinese Society of Electrical Engineering, vol. 28, no. 19, p 131-137, 2008.

[9] X.-Wang, W.-J. Lou, H.-N. Li, et al., "Wind -induced dynamic response of high-rise transmission tower under downburst wind load," Proceedings of the CSEE, vol. 43, no. 8, pp. 1520-1525, 2009.

[10] H.-F. Bai,H.-N. Li, "Simulation study of stochastic fluctuating wind field on large span electricity transmission tower-line system," Engineering Mechanics, vol. 24, no. 7, pp. 146-151, 2007.

[11] G.-F. Zhao, Q. Xie,S.-G. Liang,et al, "Wind tunnel test on windinduced nonlinear vibrations of high-voltage transmission towerline coupling system," Journal of Tongji University, vol. 37, no. 9, pp. 1157-1164, 2009

[12] S.-G. Liang,J.-H. Zhu,L.-Z. Wang, "Analysis of dynamic characters of electrical transmission tower-line system with a big span," Earthquake Engineering and Engineering Vibration, Vol.23, no.6,pp. 63-69, 2003.

[13] S.-G.Liang, L.-H. Zou,L. Zhao,et al, “Analytical model of dynamic wind loads on lattice towers," Journal of Tongji University, vol. 36, no. 2, pp. 166-171, 2008.

[14] H.-Z. Deng, X.-M. Chen,H.-M. Tu, et al., "Experimental study on model of Jiangyin long span transmission tower," Journal of Building Structures, vol. 22, no. 6, pp. 31, 2001

[15] H.-Z. Deng, R.-J. Si,X.-Y. Hu, et al., "Wind tunnel test on aeroelastic model of UHV latticed transmission tower," Journal of Tongii University, vol. 38, no. 5, pp. 673-678, 2010.

[16] R.W. Clough and J. Penzien, "Dynamics of structures," McGrawHill, New York, NY, USA, 1975

[17] Z.-Q.Chen, Wind-Induced Vibration Stability and Control of Engineering Structure. Beijing, China, 2013.

\section{ACKNOWLEDGEMENTS}

Declared none.

Received: October 16, 2014

Revised: December 23, 2014

Accepted: December 31, 2014

(C) Wu and Li; Licensee Bentham Open.

This is an open access article licensed under the terms of the Creative Commons Attribution Non-Commercial License (http://creativecommons.org/licenses/by$\mathrm{nc} / 3.0 /$ ) which permits unrestricted, non-commercial use, distribution and reproduction in any medium, provided the work is properly cited. 